Case Report

\title{
Orbital lymphoma in an elderly patient
}

\section{Ghartimagar D ${ }^{1}$, Ghosh $\mathrm{A}^{1}$, Shrestha $\mathrm{MK}^{2}$, Karki $\mathrm{S}^{1}$, Shrestha $\mathrm{S}^{3}$, Thapa $\mathrm{S}^{1}$, Talwar $\mathrm{OP}^{1}$}

${ }^{\prime}$ Department of Pathology, Manipal College of Medical Sciences, Pokhara, Nepal.

'Department of Radiology, Gandaki Medical College, Pokhara, Nepal.

${ }^{3}$ Department of Ophthalmology, Manipal College of Medical Sciences, Pokhara, Nepal.

\section{Keywords: \\ Eye lid; Lymphomas; Non-Hodgkin; Orbital}

\section{ABSTRACT}

Lymphomas of the orbit and orbital adnexae are rare tumors, comprising only $1 \%$ of all non-Hodgkin's lymphoma. Lymphomas are the most common primary orbital tumor in adults of age 60 years and older. Here we present a case of 49 year male with left upper lid swelling since 1 year who was diagnosed histopathologically as non-Hodgkin's lymphoma of orbital region.

\section{INTRODUCTION}

Orbital lymphomas are rare, comprising only $1 \%$ of all nonHodgkin's lymphoma. ${ }^{1}$ Lymphomas are the most common primary orbital tumor in adults of age 60 years and older. ${ }^{2}$ Three hundred fourteen primary orbital malignancies were reported by Margo and Mulla, 55\% of which were orbital lymphoma. ${ }^{3}$

\section{CASE REPORT}

A 49 year-old male, presented in OPD, with history of swelling of left upper eyelid (fig.1) since 1 year. He was apparently well one year back and he noticed painless

\section{Correspondence:}

Dr. Dilasma Ghartimagar, $M B B S, M D$

Department of Pathology

Manipal College of Medical Sciences, Pokhara, Nepal

Email:dilasmagm@hotmail.com swelling in left upper eyelid lateral region which gradually increased in size. There was no history of periorbital redness.

On examination, there was inferior displacement of eyelid and obstruction in upper field of vision. There was no diminution of vision, diplopia, redness of eye, discharge, grittiness, photophobia, lacrimation or trauma. On palpation the mass was smooth, firm, non tender and immobile. There was no other palpable lymphnodes. Complete blood count, chest $\mathrm{x}$-ray were within normal range and serological examination was negative.

CT impression was a minimal enhancing homogeneous soft tissue density lesion measuring $3 \times 2 \mathrm{~cm}$ involving left lacrimal gland, predominantly within the pre and postseptal extraconal space. The lesion was abutting the superior, lateral rectus muscles and extending to orbital 


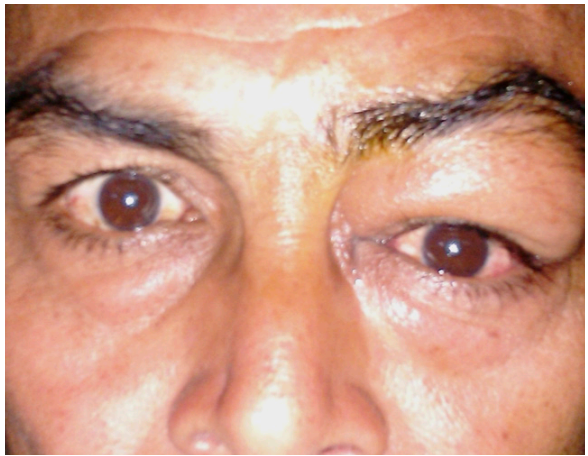

Figure 1: Patient with left upper eye lid swelling.

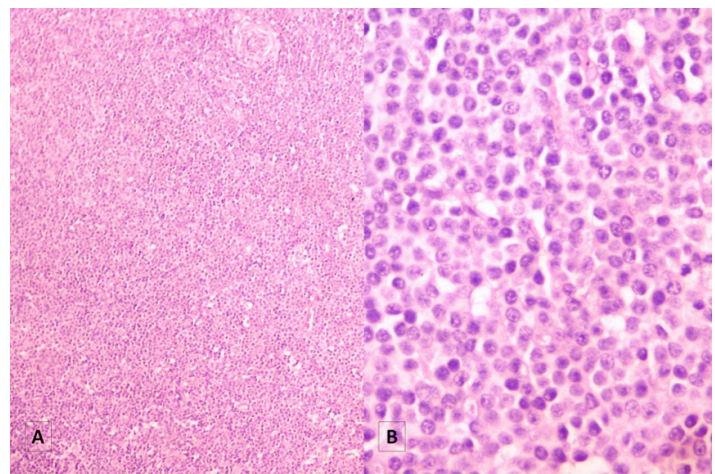

Figure 3A: Histopathological picture showing diffuse sheets of monotonous appearing non-Hodgkin's lymphoma cells (HE stain, x100). B. High power view of the same (HE stain, x400).

apex (fig. 2). Radiological differential diagnosis included lymphoma of lacrimal gland and cavernous hemangioma. Incisional biopsy done and mass sent for histopathological examination.

Grossly, the specimen consisted of a dark brown nodular tissue measuring $1.5 \times 1.5 \mathrm{~cm}$ with homogenous grey white cut surface. Microscopic examination showed monotonous lymphoid cells composed of mainly small cleaved and noncleaved cells admixed with several histiocytes and few tingible body macrophages (fig.3). Reed Sternberg cells and increased eosinophils were not seen. Histopathological diagnosis of Low grade, Non Hodgkin's Lymphoma of lacrimal gland was given.

\section{DISCUSSION}

Lymphoid proliferations of the orbit, including intraocular and ocular adnexal non-Hodgkin lymphoma (NHL), constitute a heterogeneous group of neoplasms that represent less than $1 \%$ of all NHLs and $5 \%$ to $15 \%$ of all extranodal NHLs., ${ }^{4,5}$

First described in 1952, they are the most frequent malignant tumors of the eye and ocular adnexae; in fact, in the Florida Cancer Registry, they represent up to $55 \%$ of all orbital tumors. . $^{6,7}$

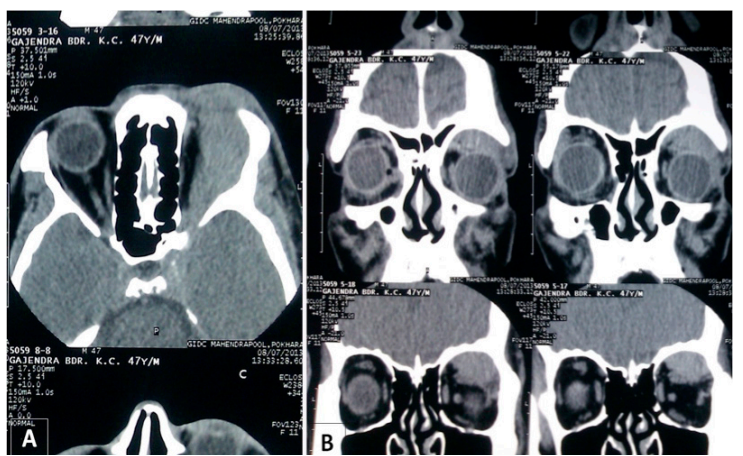

Figure 2: Coronal $(A)$ and axial (B) noncontrast CT scan images, soft tissue window, show a soft tissue density lesion with poorly defined margins in the region of left lacrimal gland.

As for all NHLs, a marked increase of the incidence of ocular adnexal NHL has also been observed. ${ }^{7}$ The clinical features and natural history of ocular adnexal lymphoma (OAL) is completely different from those of intraocular lymphoma.

Intraocular lymphoma is a subset of primary central nervous system lymphoma and intraocular involvement is found in approximately $15 \%$ of affected patients. ${ }^{4}$ The histologic subtype of intraocular lymphoma is almost always high grade and it can occur in the context of AIDS-related lympho-proliferations. ${ }^{4}$

In contrast, Ocular Adnexal Lymphomas including lesions of the conjunctiva, lacrimal gland, orbit, and eyelids are mainly low-grade tumors not associated with HIV infection. ${ }^{8}$ In our case, we had 49 years old serology negative male who presented with left upper eyelid swelling for 1 year, the swelling involved left lacrimal gland which showed low grade NHL on histopathology.

Large majority of reported OALs - between 95\% and 100\% of reported cases - correspond to the B-cell type, and 80\% of B-cell lymphomas are low grade.

The majority of non Hodgkin's lymphomas of the orbit and orbital adnexa are extranodal marginal-zone B-cell lymphomas and mucosa associated lymphoid tissue (MALT)-type lymphomas. ${ }^{1}$

Standard treatment for primary central nervous system and intraocular lymphomas is combination chemotherapy with high dose methotrexate and for low-grade ophthalmologic lymphomas it is radiotherapy. Overall prognosis of OAL is good with 5-year overall survival rate ranging between 50\% and $94 \%{ }^{4}$

\section{CONCLUSION}

Owing to non-specific clinical symptoms, some diagnostic delay may occur in orbital lymphoma. Adequate imaging 
studies followed by early surgical biopsy will contribute to early diagnosis. Radiation therapy is an effective treatment for orbital lymphoma resulting in local control in the majority of cases. It is important to continue long term follow-up of these patients to assess for local control, complications, and relapse in distant sites.

\section{REFERENCES}

1. Eckardt AM, Lemound J, Rana M, Nils-Claudius Gellrich NC. Orbital lymphoma: diagnostic approach and treatment outcome. World J Surg Oncol.2013;11:73. Crossref

2. Demirci H, Shields CL, Shields JA, Honavar SG, Mercado GJ, Tovilla JC. Orbital tumors in the older adult population. Ophthalmology 2002;109:243-8. Crossref
3. Margo CE, Mulla ZD. Malignant tumors of the orbit, analysis of the Florida cancer registry. Ophthalmology 1998;105:185-90. Crossref

4. Decaudin RD, de Cremoux P, Vincent-Salomon A, Dendale R, Rouic LL. Ocular adnexal lymphoma: a review of clinicopathologic features and treatment options. Blood. 2006;108:1451-60. Crossref

5. Lambo MJ, Brady LW, Shields CL. Lymphoid tumors of the orbit. In: Alberti WE, Sagerman RH, eds. Radiotherapy of Intraocular and Orbital Tumors. Berlin, Germany: Springer-Verlag. 1993. pp205-16. Crossref

6. Feinstein AR, Krause AC. Ocular involvement in lymphomatous disease. Am Arch Ophthalmol 1952;48:328-37. Crossref

7. Meunier J, Lumbroso-Le Rouic L, Vincent-Salomon A. Ophthalmologic and intraocular non-Hodgkins lymphoma: a large single center study of initial characteristics, natural history, and prognostic factors. Hematol Oncol. 2004;22:143-58. Crossref 